\title{
Prevalence and correlates of fatigue and its association with quality of life among clinically stable older psychiatric patients during the COVID-19 outbreak: a cross- sectional study
}

Siyun Zou ${ }^{1,2+}, \mathrm{Zi-Han} \mathrm{Liu}^{3,4,5+} \mathbb{D}^{\mathrm{D}}$, Xiaona Yan ${ }^{6+}$, Huan Wang ${ }^{7 \dagger}$, Yulong $\mathrm{Li}^{7 \dagger}$, Xiuying $\mathrm{Xu}^{6}$, Xiangdong $\mathrm{Du}^{1,2}$, Lan Zhang ${ }^{7}$, Qinge Zhang ${ }^{8^{*}}$, Todd Jackson ${ }^{9}$, Gabor S. Ungvari ${ }^{10,11}$ and Yu-Tao Xiang ${ }^{3,4,5^{*}}$

\begin{abstract}
Background: The pattern of fatigue in older psychiatric patients during the COVID-19 outbreak was unknown. This study examined the prevalence of fatigue and its association with overall quality of life (overall QOL) in clinically stable older patients with psychiatric disorders during the COVID-19 outbreak.

Methods: This was a multicenter, cross-sectional study. Fatigue, depressive symptoms, pain, insomnia symptoms, and overall QOL were assessed with standardized instruments.

Results: A total of 1063 patients were recruited. The prevalence of fatigue was 47.1\% (95\%Cl: 44.1-50.1\%). An analysis of covariance revealed that overall QOL was significantly lower in patients with fatigue compared to those without $(P=0.011)$. A multiple logistic regression analysis revealed that more severe depressive symptoms $(\mathrm{OR}=$ $1.15, P<0.001)$, insomnia symptoms $(\mathrm{OR}=1.08, P<0.001)$ and pain $(\mathrm{OR}=1.43, P<0.001)$ were significantly associated with fatigue.

Conclusions: Fatigue is common among clinically stable older patients with psychiatric disorders during the COVID-19 outbreak. Considering its negative impact on overall QOL, regular assessment of fatigue and appropriate treatment warrant attention in this subpopulation.
\end{abstract}

Keywords: Fatigue, Quality of life, Older psychiatric patients, COVID-19

\footnotetext{
*Correspondence: zqe81@126.com; xyutly@gmail.com

†Siyun Zou, Zi-Han Liu, Xiaona Yan, Huan Wang and Yulong Li contributed equally to this work.

${ }^{8}$ The National Clinical Research Center for Mental Disorders \& Beijing Key Laboratory of Mental Disorders Beijing Anding Hospital \& the Advanced Innovation Center for Human Brain Protection, Capital Medical University, School of Mental Health, Beijing, China

${ }^{3}$ Unit of Psychiatry, Institute of Translational Medicine, Faculty of Health Sciences, University of Macau, Building E12, Avenida da Universidade, Taipa, Macau SAR, China

Full list of author information is available at the end of the article
}

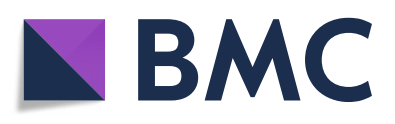

(- The Author(s). 2020 Open Access This article is licensed under a Creative Commons Attribution 4.0 International License, which permits use, sharing, adaptation, distribution and reproduction in any medium or format, as long as you give appropriate credit to the original author(s) and the source, provide a link to the Creative Commons licence, and indicate if changes were made. The images or other third party material in this article are included in the article's Creative Commons licence, unless indicated otherwise in a credit line to the material. If material is not included in the article's Creative Commons licence and your intended use is not permitted by statutory regulation or exceeds the permitted use, you will need to obtain permission directly from the copyright holder. To view a copy of this licence, visit http://creativecommons.org/licenses/by/4.0/. The Creative Commons Public Domain Dedication waiver (http://creativecommons.org/publicdomain/zero/1.0/) applies to the data made available in this article, unless otherwise stated in a credit line to the data. 


\section{Background}

Since the novel coronavirus disease 2019 (COVID-19) was first identified in Wuhan, China in December, 2019, it has been found in more than 200 countries and territories globally [55]. Mental health symptoms and related problems in different subpopulations have emerged as negative health outcomes caused by the COVID-19 pandemic [48]. Compared to the general population, patients with psychiatric disorders are more likely to experience psychological distress during the COVID-19 pandemic. Psychiatric patients could also have a higher risk of contagion due to limited awareness of selfprotection, and non-adherence to preventive public health measures [65]. Similar to patients with chronic physical illnesses, clinically stable psychiatric patients require long-term maintenance pharmacotherapy and must, therefore, regularly travel from their residences to outpatient clinics [58, 60]. However, social distancing, transportation restrictions and potential infection risks during the COVID-19 pandemic increase inconvenience and potentially compromise safety for those who have to attend psychiatric outpatient appointments [31].

Compared to their younger counterparts, older psychiatric patients are at a higher risk of COVID-19 [4] due to severe cognitive decline, poor adherence to preventive measures, poor general health, and common severe physical diseases [62]. During the COVID-19 pandemic, public transportation in many areas has been suspended and online mental health services have been widely adopted [32]. However, due to limited access to internet services and smart phones, only a small fraction of older adults can benefit from such online service provision [12]. All of these factors could trigger pre-existing psychiatric disorders and increase risk for physical and psychological distress in older psychiatric patients.

Fatigue symptoms (Fatigue hereafter) are characterized by persistent weakness or exhaustion that usually occurs in tandem with impaired cognition, physical pain and sleep problems [24]. Fatigue is a common complaint in older adults [40]. Apart from the general population, patients with psychiatric disorders such as depression, anxiety, panic, eating disorders, substance misuse disorders, and somatisation disorders often suffer from fatigue [47]. For example, the prevalence of fatigue in patients with depression or anxiety ranges from 25 to $36 \%$ [20, $37,52]$. Fatigue is associated with a range of negative health outcomes including sleep disturbances [27] and poor general health status [15]. Recent studies have found that fatigue has been common in many subgroups during the COVID-19 pandemic such as patients confirmed with COVID-19 (53.6\%) [44], medical workers [46], and students [35]. Such effects are partially due to lockdown, quarantine, social distancing, and unprecedented pressure in daily life. Previous studies mainly focused on the mental impactof the COVID-19, such as low wellbeing, neuropsychiatric symptoms, and declinedcognition in older psychiatric patients [11, 21, 36], but fatigue in thispopulation was not reported worldwide.. Furthermore, to date, the impact of fatigue on quality of life (QOL), a widely used comprehensive health outcome, of older psychiatric patients is unknown. Similarly, links between fatigue and other experiences common to this population (e.g., depressive symptoms, insomnia symptoms, and pain) warrant consideration.

Therefore, we conducted this study to investigate the prevalence of fatigue and its associations with QOL as well as depressive symptoms, insomnia symptoms, and pain in clinically stable older patients with psychiatric disorders during the COVID-19 pandemic. We hypothesized that the prevalence of fatigue in older psychiatric patients during the COVID-19 pandemic would be higher than that in general older adult population in China. In addition, depressive symptoms, insomnia symptoms and pain were expected to be associated with fatigue in older psychiatric patients during COVID-19 pandemic. Third, patients with fatigue would have a lower overall QOL than those without fatigue.

\section{Methods}

\section{Setting and sample}

This cross-sectional study was carried out between May 22 and July 15, 2020 in outpatient geriatric psychiatry clinics of four major tertiary psychiatric hospitals/centres in China (i.e., Beijing Anding Hospital, Lanzhou University Second Hospital, Guangji Hospital Affiliated to Soochow University, and Xiamen Xianyue Hospital). Patients who received maintenance treatment in the participating hospitals were consecutively enrolled. The inclusion criteria were as follows: 1) aged 50 years and older [59]; 2) diagnosed with psychiatric disorders according to the International Statistical Classification of Diseases and Related Health Problems, 10th Revision (ICD-10) [54]; 3) clinically stable based on the judgment of treating psychiatrists; and 4) able to understand and read Chinese and provide written informed consent.

All participants who agreed to participate provided written informed consent forms. This study was approved by the ethical committees of respective hospitals. All study procedures were carried out in accordance with relevant ethical guidelines in participating hospitals.

\section{Instruments}

Basic demographic and clinical characteristics including age, gender, residence, marital status, educational level, severe physical illnesses, fluctuations of psychiatric disorders, frequent use of mass media, limited access to psychiatric services, poor treatment adherence during 
the COVID-19 pandemic, and concern about COVID-19 (i.e., whether or not the patient was concerned of the COVID-19 related information during the pandemic) were collected. Due to risk of transmission during the COVID-19 outbreak, face-to-face interviews were not performed. Following other studies [34], the WeChatbased QuestionnaireStar program, a commonly used application for epidemiological surveys $[28,56]$, was used to collect data. WeChat is a widely used social communication program with more than 1 billion users in China including older patients enrolled in this research and/or their guardians.

Severity of current fatigue was assessed using a numeric rating scale (NRS) [3] from "0" (no suffering from fatigue) to "10" (unbearable suffering from fatigue) [2]. Total scores of $\geq 4$ were considered "having clinically relevant fatigue" ("having fatigue" hereafter) [43]. The self-report 9-item Patient Health Questionnaire (PHQ9), Chinese version, was used to measure severity of depressive symptoms $[6,26,61]$. Each item was scored from "0" (not at all) to " 3 " (nearly every day). The Chinese version of PHQ-9 had satisfactory psychometric properties in older Chinese samples with the Cronbach's alpha of 0.83 [61]. Severity of insomnia symptoms was assessed with the 7-item Insomnia Severity Index (ISI) [41], with each item scoring from "0" (not at all) to "4" (severe) [49]. The ISI has satisfactory psychometric properties in Chinese older population with the Cronbach's alpha of 0.81 [64]. The numeric Pain Rating Scale (NPRS) was used to assess severity of pain [18]; "0" (no pain) and "10" (worst pain imaginable) were used as anchors. The Chinese version of NPRS has been widely used in different populations $[29,30,33]$. The sum of the first two items of the World Health Organization Quality of Life-brief version (WHOQOL-BREF) [13, 19, 57] was calculated to assess patients' overall QOL, with higher scores indicating a higher overall QOL. Data on frequent use of mass media, limited access to psychiatric services, fluctuations of psychiatric disorders, concern about COVID-19 and poor treatment adherence during COVID-19 outbreak were collected from patient selfreports or their guardian's reports; fluctuations of psychiatric disorders and poor treatment adherence were confirmed by treating psychiatrists.

\section{Data analysis}

Data were analysed using the IBM Statistical Package for Social Science (SPSS) program, version 23.0. A P-P Plot analysis was performed to test normality of continuous variable distributions. To compare demographic and clinical characteristics between fatigue and no fatigue groups, Chi-square tests, independent samples $t$ tests and Mann-Whitney U Tests were used, as appropriate. A multiple logistic regression analysis, with the "Enter" method, was conducted to examine independent demographic and clinical correlates of fatigue; fatigue was the dependent variable and other measures that had $P$ values of $<0.05$ in univariate analyses were independent variables. To compare overall QOL differences between fatigue and no fatigue groups, an analysis of covariance (ANCOVA) was conducted after controlling for variables that had statistically significant differences in univariate analyses. The significance level was set at $P<0.05$ (twotailed).

\section{Results}

In total, 1068 patients were invited, of whom, 1063 met the study entry criteria and joined this study. The prevalence of fatigue (total score of $\geq 4$ ) was $47.1 \%$ (95\%CI: $44.1-50.1 \%)$ with a mean fatigue total score of 3.4 (SD = 2.7). Table 1 shows demographic and clinical characteristics of participants.

Univariate analyses revealed that fatigue was significantly associated with rural residence $(P<0.001)$, having severe physical illness $(P=0.02)$, limited access to psychiatric services $(P=0.01)$, illness worsening during COVID-19 outbreak $(P<0.001)$, having the diagnosis of major depressive disorder $(P<0.001)$, fewer years of education $(\mathrm{P}<0.001)$, and higher total scores on the PHQ-9 $(P<0.001)$, ISI $(P<0.001)$, and NPRS $(P<0.001)$. After controlling for covariates, clinically stable older psychiatric patients with fatigue reported lower overall QOL compared than those without fatigue $\left(\mathrm{F}_{(1,1063)}=6.471\right.$, $P=0.011$.

Multiple logistic regression analysis revealed more severe depressive symptoms $(\mathrm{OR}=1.15, P<0.001)$, insomnia symptoms $(\mathrm{OR}=1.08, P<0.001)$ and pain $(\mathrm{OR}=$ $1.43, P<0.001)$ were significantly associated with fatigue (Table 2).

\section{Discussion}

This was the first study that examined the prevalence of fatigue in older psychiatric patients and its impact on overall QOL during the COVID-19 outbreak. We found that $47.1 \%$ (95\%CI: $44.1-50.1 \%$ ) of clinically stable older patients with psychiatric disorders reported fatigue during the COVID-19 outbreak, which is higher than the prevalence (31.2\%, 95\%CI: 30.0-32.5\%) observed using standardized questions in the general older adults in China [40], and similar to the rate $(53.6 \%)$ found using the Fatigue Scale-14 in COVID-19 patients [44]. Although potentially informative, direct comparisons between studies using different measures of fatigue should be made with caution.

The high prevalence of fatigue in clinically stable older psychiatric patients could be due to several reasons. First, fatigue is a comorbid symptom of many psychiatric diagnoses. For instance, a study found that $60 \%$ of 
Table 1 Socio-demographical and clinical characteristics of the participants

\begin{tabular}{|c|c|c|c|c|c|c|c|c|c|}
\hline \multirow[t]{2}{*}{ Variable } & \multicolumn{2}{|c|}{$\begin{array}{l}\text { Total } \\
(N=1063)\end{array}$} & \multicolumn{2}{|c|}{$\begin{array}{l}\text { Fatigue } \\
(N=501)\end{array}$} & \multicolumn{2}{|c|}{$\begin{array}{l}\text { No Fatigue } \\
(N=562)\end{array}$} & \multicolumn{3}{|c|}{ Univariate analyses } \\
\hline & $\mathbf{N}$ & $\%$ & $\mathbf{N}$ & $\%$ & $\mathbf{N}$ & $\%$ & $x^{2}$ & df & $P$ \\
\hline Male gender & 347 & 32.6 & 157 & 31.3 & 190 & 33.8 & 0.74 & 1 & 0.391 \\
\hline Married & 961 & 90.4 & 446 & 89.0 & 515 & 91.6 & 2.09 & 1 & 0.148 \\
\hline Rural residence & 373 & 35.1 & 203 & 40.5 & 170 & 30.2 & 12.27 & 1 & $<0.001$ \\
\hline Have severe physical illness & 190 & 17.9 & 104 & 20.8 & 86 & 15.3 & 5.37 & 1 & 0.020 \\
\hline Concerned about COVID-19 & 744 & 70.0 & 347 & 69.3 & 397 & 70.6 & 0.24 & 1 & 0.624 \\
\hline Frequent use of mass media during COVID-19 outbreak & 215 & 20.2 & 99 & 19.8 & 116 & 20.6 & 0.13 & 1 & 0.721 \\
\hline Limited access to psychiatric services during COVID-19 outbreak & 367 & 34.5 & 193 & 38.5 & 174 & 31.0 & 6.70 & 1 & 0.010 \\
\hline Poor treatment adherence during COVID-19 outbreak & 365 & 34.3 & 187 & 37.3 & 178 & 31.7 & 3.75 & 1 & 0.053 \\
\hline Illness worsening during COVID-19 outbreak & 564 & 53.1 & 345 & 68.9 & 219 & 39.0 & 95.04 & 1 & $<0.001$ \\
\hline Principal psychiatric diagnosis & & & & & & & 13.17 & 1 & $<0.001$ \\
\hline MDD & 485 & 45.6 & 258 & 51.5 & 227 & 40.4 & & & \\
\hline Other diagnoses ${ }^{b}$ & 578 & 54.4 & 143 & 48.5 & 335 & 59.6 & & & \\
\hline Variable & Mean & SD & Mean & SD & Mean & SD & $t / Z$ & df & $P$ \\
\hline Age (years) & 62.80 & 9.44 & 62.41 & 9.48 & 63.15 & 9.40 & -1.28 & 1061 & 0.202 \\
\hline Education (years) & 7.96 & 4.03 & 7.51 & 4.04 & 8.37 & 3.98 & -3.94 & $-{ }^{a}$ & $<0.001$ \\
\hline PHQ-9 total score & 7.76 & 6.73 & 11.40 & 6.78 & 4.51 & 4.73 & -17.28 & $-{ }^{a}$ & $<0.001$ \\
\hline ISI total score & 8.93 & 6.36 & 11.84 & 6.11 & 6.34 & 5.40 & -14.26 & $-{ }^{a}$ & $<0.001$ \\
\hline Pain total score & 1.53 & 2.20 & 2.33 & 2.59 & 0.82 & 1.47 & -9.78 & $-{ }^{a}$ & $<0.001$ \\
\hline Overall quality of life & 6.26 & 1.56 & 5.69 & 1.55 & 6.77 & 1.38 & -12.08 & 1061 & $<0.001$ \\
\hline
\end{tabular}

Bolded values: < 0.05; COVID-19 Coronavirus Disease 2019, MDD Major depressive disorder, PHQ-9 the 9-item Patient Health Questionnaire, ISI Insomnia Severity Index, SD Standard deviation. ${ }^{a}$ Mann-Whitney U Test; ${ }^{b}$ other diagnoses included bipolar disorder, schizophrenia, organic mental disorders, etc. P-P plots revealed that among the six continuous variables (e.g., age, education years, PHQ-9 total score, ISI total score, pain total score, and overall QOL), age and overall QOL scores were normally distributed but other continuous variables had skewed distributions

psychiatric inpatients reported significant level of fatigue [53], particularly those with depressive or anxiety disorders [50]. Although patients were clinically stable during the study period, the COVID-19 outbreak and related problems such as limited access to psychiatric services and fear of transmission could have triggered certain comorbid symptoms such as fatigue, in these patients. Second, many older adults suffered from severe and/or chronic physical illnesses. Due to the suspension of public transportation and mass quarantine measures, this group may have had more difficulty attending follow-up appointments and receiving maintenance treatments, in

Table 2 Independent correlates of fatigue by multiple logistic regression analysis

\begin{tabular}{llll}
\hline Variables & \multicolumn{3}{l}{ Multiple logistic regression analysis } \\
\cline { 2 - 4 } & P value & OR & 95\% Cl \\
\hline Rural residence & 0.66 & 1.09 & $0.75-1.57$ \\
Presence of severe physical illness & 0.628 & 1.11 & $0.72-1.71$ \\
Limited access to psychiatric services during COVID-19 outbreak & 0.549 & 1.11 & $0.79-1.58$ \\
IIIness worsening during COVID-19 outbreak & 0.237 & 1.22 & $0.88-1.70$ \\
Principal psychiatric diagnosis (MDD) & 0.075 & 1.34 & 0.96 \\
Education (years) & 0.072 & 1.15 & $0.92-1.00$ \\
PHQ-9 total score & $<\mathbf{0 . 0 0 1}$ & 1.08 & $1.11-1.19$ \\
ISI total score & $<\mathbf{0 . 0 0 1}$ & 1.43 & $1.05-1.12$ \\
Pain total score & $<\mathbf{0 . 0 0 1}$ & $1.30-1.57$ \\
\hline
\end{tabular}

Bolded values: <0.05; CI Confidential interval, OR Odds ratio, MDD Major depressive disorder, PHQ-9 the 9-item Patient Health Questionnaire, ISI Insomnia Severity Index. Participating hospitals were controlled for as covariate 
turn, exacerbating their physical illnesses (e.g., cancer, hypertension, chronic pain disorder, chronic obstructive pulmonary disease) and experience of fatigue [50, 51]. Third, sedentary lifestyle, due to lack of physical exercise, was associated with fatigue [38]. As such, lack of outdoor activities and physical exercise due to quarantine measures during the COVID-19 pandemic could cause fatigue. Finally, the high mortality rate and poor prognosis of COVID-19 in older adults could lead to perceptions of health risks and psychological distress, which may have resulted in increased loneliness and fatigue [17]. Previous studies found that fatigue was positively associated with female gender and younger age [1, $14,23]$, but these results were based on general samples and assessed under "non-pandemic" conditions. In this study, however, no significant associations between fatigue and gender or age were found.

As expected, patients with more severe depressive symptoms $(\mathrm{OR}=1.15, P<0.001)$, insomnia symptoms $(\mathrm{OR}=1.08, \mathrm{P}<0.001)$ and more severe pain $(\mathrm{OR}=1.43$, $P<0.001)$ were more likely to report fatigue. Fatigue is common in depressed patients, particularly in those with comorbid somatic symptoms. Previous studies have found that many depressed patients complained of fatigue $[8,16,39]$, an effect that may be partly due to common underlying genetic factors [10]. In addition, fatigue could be induced by antidepressant medications [38]. Some studies have found insomnia is a contributing factor to fatigue [27] and improvements in sleep problems as a correlate of decreases in fatigue complaints among older adults [9]. In this study, patients reporting more severe pain were at higher risk for fatigue, a finding that is consistent with previous findings in patients with primary Sjögren's syndrome [7], cancer [45], or multiple sclerosis [25].

We found that patients with fatigue had a lower overall QOL than those without, consistent with previous findings $[25,42]$. QOL is determined by interactions between protective factors (e.g., higher economic status) and risk factors (e.g., poor physical health) [22]. Fatigue is associated with sleep disturbances, reduced energy and motivation, and cognitive dysfunctions, all of which could negatively affect daily functioning, increase physical and mental distress, and eventually lower QOL [5, $15,63]$.

The strengths of this study included its focus on an understudied, at-risk population, multi-center design, use of validated measures, and large sample size. However, several methodological limitations should also be acknowledged. First, because we focused on clinically stable older patients, findings cannot be generalized to patients in other illness stages. Second, causal relations between fatigue and other variables could not be established due to the cross-sectional study design. Third, for logistical reasons (i.e., concerns about high response burdens in a vulnerable group), some factors associated with fatigue (e.g., treatment of physical illnesses and economic status), were not examined in this study.

\section{Conclusion}

In conclusion, this was the first study that examined the prevalence of fatigue in older psychiatric patients and its impact on overall QOL during the COVID-19 outbreak. The prevalence of fatigue was $47.1 \%$, indicating that it is common among clinically stable older patients with psychiatric disorders during the COVID-19 pandemic. Given the prevalence of fatigue and its negative associations with overall QOL andother disturbances, regular screening onfatigue should be conducted in older psychiatric patients in all countriesaffected by the COVID19 pandemic.Furthermore, routine assessment of the presence and severity of fatigue shouldbe conducted in this vulnerable population, and appropriate treatments shouldbe offered to those in need.

\section{Abbreviations \\ COVID-19: Novel coronavirus disease 2019; Overall QOL: Overall quality of life; PHQ-9: The self-report 9-item Patient Health Questionnaire; ISI: The 7-item In- somnia Severity Index; NPRS: Numeric pain rating scale; FS-14: Fatigue Scale- 14; NRS: Numeric rating scale; WHOQOL-BREF: World Health Organization Quality of Life-brief version; SPSS: IBM Statistical Package for Social Science; ANCOVA: Analysis of covariance}

\section{Acknowledgements \\ None.}

\section{Authors' contributions}

Study design: Qinge Zhang, Yu-Tao Xiang. Data collection, analysis and interpretation: Zi-Han Liu, Xiuying Xu, Siyun Zou, Yulong Li, Huan Wang, Xiaona Yan, Xiang-Dong Du, Lan Zhang, Qinge Zhang. Drafting of the manuscript: Zi-Han Liu, Todd Jackson, Yu-Tao Xiang. Critical revision of the manuscript: Gabor S. Ungvari. The author(s) read and approved the final manuscript.

\section{Funding}

The study was supported by the National Science and Technology Major Project for investigational new drug (2018ZX09201-014), the Beijing Municipal Science \& Technology Commission (No. Z181100001518005), the University of Macau (MYRG2019-00066-FHS), and the Key Diagnosis and treatment Program of Suzhou (LCZX201615).

\section{Availability of data and materials}

The datasets used and/or analyzed during the current study are available from the corresponding author on reasonable request.

\section{Ethics approval and consent to participate}

All participants provided written informed consent. The study protocol was approved by the ethics committee of the University of Macau, China.

\section{Consent for publication \\ Approval of the final version for publication: all co-authors and all participants.}

\section{Competing interests}

The authors have no conflicts of interest to declare.

\section{Author details}

${ }^{1}$ Medical College of Soochow University, Suzhou, Jiangsu Province, China. ${ }^{2}$ Guangji Hospital Affiliated to Soochow University, Suzhou, Jiangsu Province, China. ${ }^{3}$ Unit of Psychiatry, Institute of Translational Medicine, Faculty of 
Health Sciences, University of Macau, Building E12, Avenida da Universidade, Taipa, Macau SAR, China. ${ }^{4}$ Center for Cognition and Brain Sciences, University of Macau, Macao SAR, China. Institute of Advanced Studies in Humanities and Social Sciences, University of Macau, Macao SAR, China. ${ }^{6}$ Department of Psychiatry, Xiamen Xianyue Hospital, Xiamen, China. ${ }^{7}$ Department of Psychiatry, Lanzhou University Second Hospital, Lanzhou, Gansu Province, China. ${ }^{8}$ The National Clinical Research Center for Mental Disorders \& Beijing Key Laboratory of Mental Disorders Beijing Anding Hospital \& the Advanced Innovation Center for Human Brain Protection, Capital Medical University, School of Mental Health, Beijing, China. ${ }^{9}$ Department of Psychology, University of Macau, Macau SAR, China. ${ }^{10}$ Division of Psychiatry, School of Medicine, University of Western Australia, Perth, Australia. ${ }^{11}$ University of Notre Dame Australia, Fremantle, Australia.

\section{Received: 23 August 2020 Accepted: 13 November 2020} Published online: 18 December 2020

\section{References}

1. Bensing JM, Hulsman RL, Schreurs KM. Gender differences in fatigue: biopsychosocial factors relating to fatigue in men and women. Med Care. 1999;37(10):1078-83. https://doi.org/10.1097/00005650-199910000-00011.

2. Berger AM, Abernethy AP, Atkinson A, Barsevick AM, Breitbart WS, Cella D, et al. NCCN clinical practice guidelines Cancer-related fatigue. J Natl Compr Cancer Netw. 2010;8(8):904-31. https://doi.org/10.6004/jnccn.2010.0067.

3. Butt Z, Wagner LI, Beaumont JL, Paice JA, Peterman AH, Shevrin D, et al. Use of a single-item screening tool to detect clinically significant fatigue, pain, distress, and anorexia in ambulatory cancer practice. J Pain Symptom Manag. 2008;35(1):20-30. https://doi.org/10.1016/j.jpainsymman.2007.02.040.

4. CDC. (2020). Older adults. Retrieved from.

5. Cha B-K. Factors Affecting Health-related Quality of Life in Women Undergraduates. J Korean Acad Fundam Nurs. 2013:20. https://doi.org/10. 7739/jkafn.2013.20.4.400.

6. Chen M, Sheng L, Qu S. Diagnostic test of screening depressive disorder in general hospital with the patient health questionnaire (in Chinese). Chinese Mental Health. 2015;29(4):241-5.

7. Conrad R, Geiser F, Mücke M. Pain and fatigue - a systematic review. Z Psychosom Med Psychother. 2018;64(4):365-79. https://doi.org/10.13109/ zptm.2018.64.4.365.

8. Conradi HJ, Ormel J, de Jonge P. Presence of individual (residual) symptoms during depressive episodes and periods of remission: a 3-year prospective study. Psychol Med. 2011:41(6):1165-74. https://doi.org/10.1017/s0033291710001911.

9. Cooke KM, Kreydatus MA, Atherton A, Thoman EB. The effects of evening light exposure on the sleep of elderly women expressing sleep complaints. J Behav Med. 1998;21(1):103-14. https://doi.org/10.1023/a:1018719722614.

10. Corfield EC, Martin NG, Nyholt DR. Shared genetic factors in the cooccurrence of depression and fatigue. Twin Res Hum Genet. 2016;19(6):610 8. https://doi.org/10.1017/thg.2016.79.

11. Di Santo SG, Franchini F, Filiputti B, Martone A, Sannino S. The Effects of COVID-19 and Quarantine Measures on the Lifestyles and Mental Health of People Over 60 at Increased Risk of Dementia. Front Psychiatry. 2020;11: 578628. https://doi.org/10.3389/fpsyt.2020.578628.

12. Du R-H, Liang L-R, Yang C-Q, Wang W, Cao T-Z, Li M, et al. Predictors of mortality for patients with COVID-19 pneumonia caused by SARS-CoV-2: a prospective cohort study. Eur Respir J. 2020;55(5):2000524. https://doi.org/ 10.1183/13993003.00524-2020

13. Fang JQ, Hao YA. Reliability and validity for Chinese version of WHO quality of life scale (in Chinese). Chin Ment Health J. 1999;13(4):203-9.

14. Faro M, Sàez-Francás N, Castro-Marrero J, Aliste L, Fernández de Sevilla T, Alegre J. Gender differences in chronic fatique syndrome. Reumatol Clin. 2016;12(2):72-7. https://doi.org/10.1016/j.reuma.2015.05.007.

15. Galland-Decker C, Marques-Vidal P, Vollenweider P. Prevalence and factors associated with fatigue in the Lausanne middle-aged population: a population-based, cross-sectional survey. BMJ Open. 2019;9(8):e027070. https://doi.org/10.1136/bmjopen-2018-027070.

16. Ghanean H, Ceniti AK, Kennedy SH. Fatigue in patients with major depressive disorder: prevalence, burden and pharmacological approaches to management. CNS Drugs. 2018;32(1):65-74. https://doi.org/10.1007/s40263018-0490-z.

17. Griffin SC, Williams AB, Mladen SN, Perrin PB, Dzierzewski JM, Rybarczyk BD. Reciprocal effects between loneliness and sleep disturbance in older Americans. J Aging Health. 2019; 0898264319894486.
18. Haefeli M, Elfering A. Pain assessment. Eur Spine J. 2006;15(1):S17-24.

19. Harper A, Power M, Grp W. Development of the World Health Organization WHOQOL-BREF quality of life assessment. Psychol Med. 1998, 28;(3):551-8. https://doi.org/10.1017/S0033291798006667.

20. Harvey SB, Wadsworth M, Wessely S, Hotopf M. The relationship between prior psychiatric disorder and chronic fatigue: evidence from a national birth cohort study. Psychol Med. 2008;38(7):933-40. https://doi.org/10.1017/ s0033291707001900.

21. Hashimoto M, Suzuki M, Hotta M, Nagase A, Yamamoto Y, Hirakawa N, et al. The influence of the COVID-19 outbreak on the lifestyle of older patients with dementia or mild cognitive impairment who live alone. Front Psychiatry. 2020;11:570580. https://doi.org/10.3389/fpsyt.2020.570580.

22. Hatoum HT, Kong SX, Kania CM, Wong JM, Mendelson WB. Insomnia, health-related quality of life and healthcare resource consumption. Pharmacoeconomics. 1998;14(6):629-37.

23. Husain AF, Stewart K, Arseneault R, Moineddin R, Cellarius V, Librach SL, Dudgeon D. Women experience higher levels of fatigue than men at the end of life: a longitudinal home palliative care study. J Pain Symptom Manag. 2007; 33(4):389-97. https:/doi.org/10.1016/j.jpainsymman.2006.09.019.

24. Keiji F, Straus SE, Hickie I, Dobbins JG, Komaroff A, Group, I. C. F. S. S. The Chronic Fatique Syndrome: A Comprehensive Approach to Its Definition and Study. Ann Intern Med. 1994;121(12):953-9. https://doi.org/10.7326/ 0003-4819-121-12-199412150-00009.

25. Kratz AL, Braley TJ, Foxen-Craft E, Scott E, Murphy JF 3rd, Murphy SL. How Do pain, fatigue, depressive, and cognitive symptoms relate to well-being and social and physical functioning in the daily lives of individuals with multiple sclerosis? Arch Phys Med Rehabil. 2017;98(11):2160-6. https://doi. org/10.1016/j.apmr.2017.07.004

26. Kroenke K, Spitzer RL, Williams JB. The PHQ-9: validity of a brief depression severity measure. J Gen Intern Med. 2001;16(9):606-13. https://doi.org/10. 1046/j.1525-1497.2001.016009606.x

27. Lavidor M, Weller A, Babkoff H. How sleep is related to fatigue. $\mathrm{Br} J$ Health Psychol. 2003;8(1):95-105. https://doi.org/10.1348/135910703762879237.

28. Li F, Wu JF, Mai XH, Ning K, Chen KY, Chao L, Zheng X. Internalized homophobia and depression in homosexuals: the role of self-concept clarity (in Chinese). Chinese J Clin Psychol. 2016;24(3):475-9. https://doi.org/10. 16128/j.cnki.1005-3611.2016.03.020

29. Li L, Herr K, Chen P. Postoperative pain assessment with three intensity scales in Chinese elders. J Nurs Scholarsh. 2009;41(3):241-9.

30. Li L, Liu X, Herr K. Postoperative pain intensity assessment: a comparison of four scales in Chinese adults. Pain Med. 2007;8(3):223-34.

31. Li W, Yang Y, Liu Z-H, Zhao Y-J, Zhang Q, Zhang L, et al. Progression of mental health services during the COVID-19 outbreak in China. Int J Biol Sci. 2020;16(10):1732. https://doi.org/10.7150/ijbs.45120 eCollection 2020.

32. Liu S, Yang L, Zhang C, Xiang YT, Liu Z, Hu S, et al. Online mental health services in China during the COVID-19 outbreak. Lancet Psychiatry. 2020; 7(4):e17-8. https://doi.org/10.1016/s2215-0366(20)30077-8.

33. Liu X-Q, Li L. The selection of pain intensity assessment scales in Chinese elders (in Chinese). Chin J Nurs. 2004;39(3):165-7.

34. Lu W, Wang H, Lin Y, Li L. Psychological status of medical workforce during the COVID-19 pandemic: a cross-sectional study. Psychiatry Res. 2020;288: 112936. https://doi.org/10.1016/j.psychres.2020.112936.

35. Majumdar P, Biswas A, Sahu S. COVID-19 pandemic and lockdown: cause of sleep disruption, depression, somatic pain, and increased screen exposure of office workers and students of India. Chronobiol Int. 2020:1-10. https:// doi.org/10.1080/07420528.2020.1786107.

36. Manca R, De Marco M, Venneri A. The Impact of COVID-19 Infection and enforced prolonged social isolation on neuropsychiatric symptoms in older adults with and without dementia: a review. Front Psychiatry. 2020;11: 585540. https://doi.org/10.3389/fpsyt.2020.585540.

37. Manu P, Matthews DA, Lane TJ. The mental health of patients with a chief complaint of chronic fatigue. A prospective evaluation and follow-up. Arch Intern Med. 1988;148(10):2213-7.

38. Marin H, Menza MA. Specific treatment of residual fatigue in depressed patients. Psychiatry (Edgmont). 2004;1(2):12-8.

39. Mclntyre R, Kennedy S, Bagby RM, Bakish D. Assessing full remission. J Psychiatry Neurosci. 2002;27(4):235-9.

40. Meng $\mathrm{H}$, Hale L, Friedberg F. Prevalence and predictors of fatigue in middle-aged and older adults: evidence from the health and retirement study. J Am Geriatr Soc. 2010;58(10):2033-4. https://doi.org/10.1111/j.15325415.2010.03088.x 
41. Morin CM. Insomnia: psychological assessment and management. New York: Guilford Press; 1993.

42. Nunes MDR, Jacob E, Bomfim EO, Lopes-Junior LC, de Lima RAG, FloriaSantos M, Nascimento LC. Fatigue and health related quality of life in children and adolescents with cancer. Eur J Oncol Nurs. 2017;29:39-46. https://doi.org/10.1016/j.ejon.2017.05.001.

43. Oldenmenger WH, de Raaf PJ, de Klerk C, van der Rijt CC. Cut points on 010 numeric rating scales for symptoms included in the Edmonton symptom assessment scale in cancer patients: a systematic review. J Pain Symptom Manag. 2013;45(6):1083-93. https://doi.org/10.1016/j.jpainsymman.2012.06. 007.

44. Qi R, Chen W, Liu S, Thompson PM, Zhang LJ, Xia F, et al. Psychological morbidities and fatigue in patients with confirmed COVID-19 during disease outbreak: prevalence and associated biopsychosocial risk factors. medRxiv. 2020. https://doi.org/10.1101/2020.05.08.20031666.

45. Romero SAD, Jones L, Bauml JM, Li QS, Cohen RB, Mao JJ. The association between fatigue and pain symptoms and decreased physical activity after cancer. Support Care Cancer. 2018;26(10):3423-30. https://doi.org/10.1007/ s00520-018-4203-4.

46. Sasangohar F, Jones SL, Masud FN, Vahidy FS, Kash BA. Provider burnout and fatigue during the COVID-19 pandemic: lessons learned from a highvolume intensive care unit. Anesth Analg. 2020;131(1):106-11. https://doi. org/10.1213/ane.0000000000004866.

47. Sharpe M, Wilks D. Fatigue. Bmj. 2002;325(7362):480-3. https://doi.org/10. 1136/bmj.325.7362.480.

48. Shi L, Lu ZA, Que JY, Huang XL, Liu L, Ran MS, et al. Prevalence of and risk factors associated with mental health symptoms among the general population in China during the coronavirus disease 2019 pandemic. JAMA Netw Open. 2020;3(7):e2014053. https://doi.org/10.1001/jamanetworkopen. 2020.14053.

49. Smith MT, Wegener ST. Measures of sleep: the insomnia severity index, medical outcomes study (MOS) sleep scale, Pittsburgh sleep diary (PSD), and Pittsburgh sleep quality index (PSQI). Arthr Care Res. 2003;49(S5):S18496. https://doi.org/10.1002/art.11409.

50. Torossian M, Jacelon CS. Chronic illness and fatigue in older Individuals: A Systematic Review. Rehabil Nurs. 2020. https://doi.org/10.1097/rnj. 0000000000000278.

51. Tralongo $P$, Respini D, Ferraù F. Fatigue and aging. Crit Rev Oncol Hematol. 2003;48(Suppl):S57-64. https://doi.org/10.1016/j.critrevonc.2003.07.003.

52. Watanabe N, Stewart R, Jenkins R, Bhugra DK, Furukawa TA. The epidemiology of chronic fatigue, physical illness, and symptoms of common mental disorders: a cross-sectional survey from the second British National Survey of psychiatric morbidity. J Psychosom Res. 2008;64(4):35762. https://doi.org/10.1016/j.jpsychores.2007.12.003.

53. Waters F, Naik N, Rock D. Sleep, fatigue, and functional health in psychotic patients. Schizophr Res Treatment. 2013;2013:425826. https://doi.org/10. 1155/2013/425826

54. World Health Organization. The ICD-10 classification of mental and behavioural disorders: clinical descriptions and diagnostic guidelines. Geneva: World Health Organization; 1992.

55. World Health Organization. (2020). WHO Coronavirus Disease (COVID-19) Dashboard. https://covid19.who.int/ (Accessed 31 July 2020).

56. Xi X, Liu Y. The appliation of Wechat platform and Wenjuanxing in cognitive training among psychiatric nurse, cleaning staff and patients (in Chinese). Nurs Pract Res. 2017;14(21):114-7.

57. Xia P, Li N, Hau K-T, Liu C, Lu Y. Quality of life of Chinese urban community residents: a psychometric study of the mainland Chinese version of the WHOQOL-BREF. BMC Med Res Methodol. 2012;12(1):37. https://doi.org/10. 1186/1471-2288-12-37.

58. Xiang Y-T, Yu X, Sartorius N, Ungvari GS, Chiu HF. Mental health in China: challenges and progress. Lancet. 2012;380(9855):1715-6.

59. Xiang YT, Buchanan RW, Ungvari GS, Chiu HF, Lai KY, Li YH, et al. Use of clozapine in older Asian patients with schizophrenia between 2001 and 2009. PLoS One. 2013;8(6):e66154. https://doi.org/10.1371/journal.pone. 0066154.

60. Xiang YT, Ng CH, Yu X, Wang G. Rethinking progress and challenges of mental health care in China. World Psychiatry. 2018;17(2):231.

61. Xu Y, Wu HS, Xu YF. Application of the patient health questionnaire depression scale (PHQ-9) in the elderly in the community_- - reliability and validity analysis (in Chinese). Shanghai Arch Psychiatry. 2007;5:257-9.
62. Yang Y, Li W, Zhang Q, Zhang L, Cheung T, Xiang YT. Mental health services for older adults in China during the COVID-19 outbreak. Lancet Psychiatry. 2020;7(4):e19. https://doi.org/10.1016/s2215-0366(20)30079-1.

63. Yoo EH, Choi ES, Cho SH, Do JH, Lee SJ, Kim JH. Comparison of fatigue severity and quality of life between unexplained fatigue patients and explained fatigue patients. Korean J Fam Med. 2018;39(3):180-4. https://doi. org/10.4082/kjfm.2018.39.3.180.

64. Yu DS. Insomnia severity index: psychometric properties with Chinese community-dwelling older people. J Adv Nurs. 2010;66(10):2350-9. https:// doi.org/10.1111/j.1365-2648.2010.05394.X.

65. Zhu Y, Chen L, Ji H, Xi M, Fang Y, Li Y. The risk and prevention of novel coronavirus pneumonia infections among inpatients in psychiatric hospitals. Neurosci Bull. 2020. https://doi.org/10.1007/s12264-020-00476-9.

\section{Publisher's Note}

Springer Nature remains neutral with regard to jurisdictional claims in published maps and institutional affiliations.
Ready to submit your research? Choose BMC and benefit from:

- fast, convenient online submission

- thorough peer review by experienced researchers in your field

- rapid publication on acceptance

- support for research data, including large and complex data types

- gold Open Access which fosters wider collaboration and increased citations

- maximum visibility for your research: over $100 \mathrm{M}$ website views per year

At BMC, research is always in progress.

Learn more biomedcentral.com/submissions 